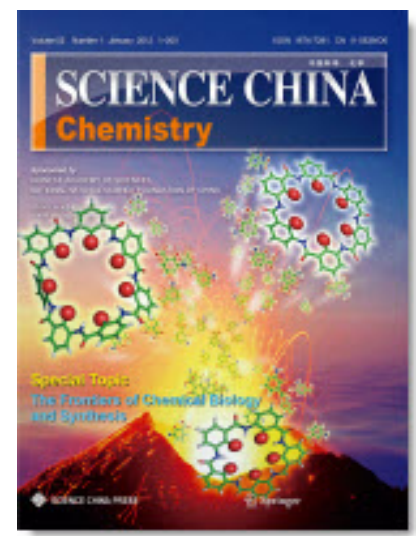

\title{
Electro-oxidation of Hydrazine Shows Marcusian Electron Transfer Kinetics
}

\begin{tabular}{|c|c|}
\hline Journal: & SCIENCE CHINA Chemistry \\
\hline Manuscript ID & SCC-2020-0998.R1 \\
\hline Manuscript Type: & Article \\
\hline $\begin{array}{r}\text { Date Submitted by the } \\
\text { Author: }\end{array}$ & 29-Sep-2020 \\
\hline Complete List of Authors: & $\begin{array}{l}\text { Miao, Ruiyang; University of Oxford, Department of Chemistry } \\
\text { Chen, Lifu; University of Oxford, Department of Chemistry } \\
\text { Compton, Richard; University of Oxford, Department of Chemistry }\end{array}$ \\
\hline Keywords: & $\begin{array}{l}\text { Hydrazine, Electrode kinetics, Transfer coefficient, Butler-Volmer theory, } \\
\text { Marcus-Hush theory }\end{array}$ \\
\hline Speciality: & Analytical Chemistry \\
\hline
\end{tabular}

\section{SCHOLARONE \\ Manuscripts}




\title{
Electro-oxidation of Hydrazine Shows Marcusian Electron Transfer Kinetics
}

\author{
Ruiyang Miao, Lifu Chen, Richard G Compton* \\ Department of Chemistry, Physical and Theoretical Chemistry Laboratory, University \\ of Oxford, South Parks Road, Oxford OX1 3QZ, UK \\ *Corresponding author \\ Email: richard.compton@chem.ox.ac.uk
}

Phone: +44 (0) $1865275957 \quad$ Fax: +44 (0) 1865275410

For submission to Science China Chemistry 


\begin{abstract}
Although hydrazine $\left(\mathrm{N}_{2} \mathrm{H}_{4}\right)$ oxidation in an electrochemical environment has been of great interest for years its intrinsic electron transfer kinetics remain uncertain. We report that the phenomenological Butler-Volmer (BV) theory is not appropriate for interpreting the process of hydrazine oxidation for which an astonishingly wide range of transfer coefficients, Tafel slopes and diffusion coefficient have been previously reported. Rather Tafel analysis for voltammetry recorded at Glassy Carbon (GC) electrodes reveals a strong potential dependence of the anodic transfer coefficient, consistent with the symmetric Marcus-Hush (sMH) theory. According to the relationship $\beta=\frac{\lambda+F E_{f}^{0}}{2 \lambda}-\frac{F}{2 \lambda} E$, the reorganization energy $(0.35 \pm 0.07 \mathrm{eV})$ and an approximate formal potential of the rate-determining first electron transfer were successfully extracted from the voltammetric responses.
\end{abstract}

Keywords: Hydrazine; Electrode kinetics; Transfer coefficient; Butler-Volmer theory; Marcus-Hush theory 


\section{Introduction}

Whilst the chemical oxidation of hydrazine, $\mathrm{N}_{2} \mathrm{H}_{4}$, historically helped to launch the V2 rockets developed in Peenemunde by Wernher von Braun[1], the electro-oxidation of hydrazine has considerable modern interest in the form of a valuable anodic reaction for use in some practical fuel cells[2-4]. Accordingly, the latter has received extensive attention especially from the applications perspective. Of underpinning fundamental interest and importance is the rate of the heterogeneous electron transfer involved in the electro-oxidation, thought to display a high over-potential, and hence electrochemically irreversible kinetics implying that the latter are slow compared to prevailing rates of mass transport on many electrodes made of diverse materials. This has led to the design and use of surfaces that catalyse the oxidation notably through the adsorptive stabilisation of reactive intermediates on the formation of di-nitrogen from hydrazine, involving the loss of four electrons and four protons from the latter.

In this context it is of interest to consider the intrinsic electron transfer behaviour of $\mathrm{N}_{2} \mathrm{H}_{4}$ on surfaces where adsorption effects are reported to be minimal[5]. Accordingly, we have investigated the electron transfer kinetics of hydrazine at carbon electrodes as an essential prerequisite underpinning any mechanistic study of active electro-catalysts. The oxidation of hydrazine at carbon electrodes has mostly, been studied from the perspective of developing the chemical sensors demanded by society because of the high toxicity of hydrazine and where amperometric approaches to sensing are sought for reasons for sensitivity and cost effectiveness[6, 7].

Hydrazine is protonated in aqueous solution at $\mathrm{pH}$ values below $c a .8$ since the $\mathrm{pK}_{\mathrm{a}}$ is 
reported as 8.1 at $25{ }^{\circ} \mathrm{C}[8-10]$ where the electrochemical oxidation likely requires deprotonation to take place in a chemical step preceding the electron transfer. As the first electron transfer is rate-determining $[11,12]$, the reaction mechanism is generally given as

$$
\begin{gathered}
\mathrm{N}_{2} \mathrm{H}_{5}^{+} \rightleftarrows \mathrm{N}_{2} \mathrm{H}_{4}+\mathrm{H}^{+} \\
\mathrm{N}_{2} \mathrm{H}_{4} \stackrel{\text { slow }}{\longrightarrow} \mathrm{N}_{2} \mathrm{H}_{4}^{+}+e \\
\mathrm{~N}_{2} \mathrm{H}_{4}^{+} \stackrel{\text { fast }}{\longrightarrow} N_{2}+4 H^{+}+3 e
\end{gathered}
$$

and in which the chemical step contributes additional over-potential to the electrode process and in which the possibility of concerted electron and proton transfer cannot be excluded.

Accordingly, for electrochemical applications hydrazine is generally used and studied under conditions of high $\mathrm{pH}$ where it is deprotonated in bulk solution. Perusal of the literature[13-15] shows that on Glassy Carbon (GC) whilst clearly defined and reproducible voltammetric oxidation waves are seen they have a characteristically exceptionally 'drawn out' shape even beyond that expected for a typical electrochemically highly irreversible process. Moreover, the literature shows a startling and unusual diversity of values reported for the diffusion coefficient of hydrazine when measured electrochemically and typically inferred from the magnitude of the voltammetric currents flowing. Table S1 in the SI Section 1 summarises some of the reported values, which span the range from $7.82 \times 10^{-7}$ to $4.10 \times 10^{-5} \mathrm{~cm}^{2} / \mathrm{s}$ much greater than typically expected for quantitative electrochemistry.

Hitherto the voltammetry of hydrazine, as often attempted, has been interpreted as a 4- 
electron oxidation in which the first electron transfer is slow and rate-determining and governed by phenomenological Butler-Volmer (BV) kinetics[16] usually with a transfer coefficient below the value of 0.5 although Table S1 shows a wide range of reported values. However in this paper we show that analysis of the measured voltammetric wave-shapes reveals a strong potential dependence of the observed anodic transfer coefficient with the value decreasing linearly with increasingly positive overpotential. Accordingly the data is further and successfully analysed using MarcusHush $(\mathrm{MH})$ theory $[17,18]$ revealing a rather low value for the re-organisation energy associated with the first electron transfer as compared to many in the literature. Whilst the equivalence - and hence indistinguishability - of BV and $\mathrm{MH}$ theories of electron transfer from solution phase species is established for large reorganisation energies significant differences can appear for lower values[19]. Under the latter conditions a reduced limiting current governed by the rate of electron transfer kinetics and not the rate of diffusion is seen at microelectrodes[19]; in the present work an analogous observation is made in respect of the voltammetric peak currents resulting from the oxidation of hydrazine at carbon macro-electrodes and the results quantified. These observations may explain the varying diffusion coefficients (and Tafel slopes) reported in the literature (see Table S1) as well as explaining the intrinsically slow kinetics of hydrazine oxidation in the absence of adsorptive catalysis.

\section{Experimental}

\section{Chemicals}

Potassium monohydrogen phosphate $\left(\mathrm{K}_{2} \mathrm{HPO}_{4}, 98 \%\right)$, potassium dihydrogen phosphate 
$\left(\mathrm{KH}_{2} \mathrm{PO}_{4}, 99 \%\right)$, potassium chloride $(\mathrm{KCl}, 99 \%)$, potassium hydroxide $(\mathrm{KOH}, 85 \%)$ and hydrazine $\left(\mathrm{N}_{2} \mathrm{H}_{4}, 99 \%\right)$ were obtained from Sigma-Aldrich and used without further purification. Phosphate buffer solutions (PBS) of different concentrations $(0.1$, 0.3 and $0.5 \mathrm{M}$ ) were prepared by mixing aqueous $\mathrm{K}_{2} \mathrm{HPO}_{4}$ and $\mathrm{KH}_{2} \mathrm{PO}_{4}$ solutions. Nitrogen gas $\left(\mathrm{N}_{2}\right)$ was supplied from BOC, U.K. All solutions were prepared with deionised water of resistivity $18.2 \mathrm{M} \Omega \mathrm{cm}\left(25^{\circ} \mathrm{C}\right.$, Millipore $)$.

\section{Cyclic voltammetry of hydrazine oxidation at a GC electrode}

A three-electrode system in a Faraday cage was employed for cyclic voltammetry (CV) experiments at $25{ }^{\circ} \mathrm{C}$, measured using a $\mu$ Autolab II potentiostat (Metrohm-Autolab $\mathrm{BV}$, Netherlands). The working electrode was a $\mathrm{GC}$ electrode of diameter $3 \mathrm{~mm}(\mathrm{CH}$ Instruments Inc., USA), which was polished with alumina slurries of decreasing particle sizes: 1.0, 0.3 and $0.05 \mu \mathrm{m}$ (Buehler Ltd., USA) before use. The reference electrode was a standard saturated calomel electrode SCE (BASi Inc., Japan) and the counter electrode was a graphite rod of diameter $6 \mathrm{~mm}$ (Sigma-Aldrich Ltd., UK). The aqueous electrolyte used was $1.5 \mathrm{mM} \mathrm{N}_{2} \mathrm{H}_{4}$ supported by $0.1 \mathrm{M}$ PBS (pH 9). Before the electrochemical measurement, the electrolyte was thoroughly out-gassed and saturated with high-purity $\mathrm{N}_{2}$ for 15 mins to remove the dissolved $\mathrm{O}_{2}$ fully and then maintained under a $\mathrm{N}_{2}$ atmosphere during the measurement. The control experiment was conducted without $\mathrm{N}_{2} \mathrm{H}_{4}$. A series of analogous experiments were conducted in various supporting electrolytes (0.3 M PBS, 0.5 M PBS as well as $0.5 \mathrm{M}$ PBS with the addition of $0.2 \mathrm{M}$ $\mathrm{KCl})$ at $\mathrm{pH} 9$.

\section{Theory}


Heterogeneous electron transfer processes in electrochemistry are typically interpreted in terms of the Butler-Volmer[20, 21] and/or Marcus-Hush (symmetric and asymmetric) $[18,19,22]$ models. These are summarised in the following before subsequently being applied to hydrazine oxidation.

The rate of an interfacial electrochemical reaction can be expressed as:

$$
j=k(n)[\text { reactant }]_{0}^{n}
$$

where $j$ is the flux of reactant undergoing electrolysis, $n$ the order of the reactant and $[\text { reactant }]_{0}$ the surface concentration of the reactant.

For a one-electron redox reaction

$$
A-e \underset{k_{\text {red }}}{\stackrel{k_{o x}}{\rightleftarrows}} B
$$

where $k_{o x}$ and $k_{\text {red }}$ are the rate constants for the oxidation and reduction respectively. Thus, the flux can be written for the net process:

$$
j=k_{o x}[A]_{0}-k_{\text {red }}[B]_{0}
$$

where $[A]_{0}$ and $[B]_{0}$ are the surface concentrations of the species $\mathrm{A}$ and $\mathrm{B}$ respectively. The rate constants can be described by either the phenomenological Butler-Volmer equation or the microscopic Marcus-Hush approach as summarised below.

\section{The Butler-Volmer (BV) model}

The best established theoretical model is the phenomenological Butler-Volmer (BV) theory, developed independently by Butler and by Volmer in the early 1930s[23, 24]. The commonly adopted BV formalism, and applied to countless redox systems, is parameterised in terms of the standard heterogeneous rate constant $\left(k_{0}\right)$, the formal 
potential $\left(E_{f}^{0}\right)$ and the transfer coefficients $(\alpha$ and $\beta$ ) that typically take potentialindependent values close to 0.5 , for a simple one-electron transfer process. Thus, the well-known expressions based on BV for the reductive and oxidative rate constants $\left(k_{r e d}^{B V}, k_{o x}^{B V}\right)$ are given by:

$$
\begin{aligned}
& k_{\text {red }}^{B V}=k_{0} \exp \left[-\frac{\alpha F}{R T}\left(E-E_{f}^{0}\right)\right] \\
& k_{\text {ox }}^{B V}=k_{0} \exp \left[+\frac{\beta F}{R T}\left(E-E_{f}^{0}\right)\right]
\end{aligned}
$$

where $F$ is the Faraday constant, $R$ the gas constant, $T$ the absolute temperature and $E$ the applied potential.

However, the macroscopic BV model is of limited use for prediction due to its empiricism, notwithstanding its easy implementation and ubiquity of application especially in terms of parameterising voltammetry. On one hand, the transfer coefficient, indicating the 'position' of the transition state as 'reactant-like' or 'product-like'[25, 26], is not quantitative but qualitative, which precludes further physical insight into the molecular process under study. On the other, the electron transfer rate constant increases exponentially with the over-potential boundlessly - a prediction that deviates from experimental observations. The latter can reflect both diffusional limitation of the surface concentrations leading to apparent deviations and/or also, most importantly, a genuine potential dependence of the transfer coefficient as best seen for surface bound species where diffusional effects do not operate as well as limitations resulting from finite electron transfer kinetics even at high over-potentials. The latter requires the adoption of Marcus-Hush kinetics. 


\section{The Marcus-Hush (MH) model}

In the 1950s, Marcus[27] developed his famous microscopic model for the analysis of electron transfer kinetics in outer-sphere homogeneous reactions, where the molecular nature of the system was characterized in terms of the reorganization energy $(\lambda)$ and the reaction Gibbs energy change $(\Delta G)$. The reorganization energy is defined as the Gibbs energy required to distort the atomic positions of the reactant molecule and its solvation shell to those of the product in its relaxed nuclear configuration[28]. It is reflected in intramolecular vibrations leading to changes in bond lengths and angles (the inner-sphere reorganization energy, $\lambda_{i}$ ) as well as the changes in the polarization of solvent molecules (the outer-sphere reorganization energy, $\lambda_{o}$ ).

The Marcus theory was developed and extended by Hush especially from a chemical perspective[29, 30], whilst in the 1990s, Chidsey's work[17] clarified the symmetry and thermodynamic consistency of the Marcus-Hush model, conditional on the metal electrode having a continuum of electronic states. Thus, the well-known symmetric Marcus-Hush (sMH) model was established and widely employed, assuming the Gibbs energy parabolae of the reductants and oxidants to have equal curvature. Hence, the Gibbs energy of activation, $\Delta G^{\dagger}$ is given by:

$$
\Delta G^{\dagger}=\frac{(\lambda+\Delta G)^{2}}{4 \lambda}
$$

The electrons in the electrode are thought to form a continuum of states $(\varepsilon)$ in the heterogeneous electron transfer reactions in accordance with the Fermi-Dirac distribution. The electrochemical rate constants based on $\mathrm{sMH}\left(k_{r e d}^{M H}, k_{o x}^{M H}\right)$ are given by: 


$$
\begin{gathered}
k_{\text {red }}^{M H}=k_{0} \frac{S_{r e d}(\eta, \Lambda)}{S_{r e d}(0, \Lambda)} \\
k_{o x}^{M H}=k_{0} \frac{S_{o x}(\eta, \Lambda)}{S_{o x}(0, \Lambda)}
\end{gathered}
$$

where $k_{\text {red } / o x}^{M H}$ is dependent on the standard rate constant $k_{0}$, the dimensionless potential $\eta$ as well as the dimensionless reorganization $\Lambda$, and $S_{\text {red/ox }}(\eta, \Lambda)$ are integrals:

$$
S_{\text {red/ox }}(\eta, \Lambda)=\int_{-\infty}^{+\infty} \frac{\exp \left[-\Delta G_{\text {sym,red/ox }}^{\dagger}(x) / R T\right]}{1+\exp (\mathrm{m} x)} d x
$$

and where $\Delta G_{s y m, r e d / o x}^{\dagger}(x)$ is the activation Gibbs energy of the electroreduction/oxidation process for each electronic level:

$$
\frac{-\Delta G_{s y m, r e d / o x}^{\dagger}(x)}{R T}=\frac{\Lambda}{4}\left(1 \pm \frac{\eta+x}{\Lambda}\right)^{2}
$$

where

$$
\begin{gathered}
\eta=\frac{F}{R T}\left(E-E_{f}^{0}\right) \\
x=\frac{F}{R T}(\varepsilon-E) \\
\Lambda=\frac{F}{R T} \lambda
\end{gathered}
$$

The upper sign in $\mathrm{m}$ or \pm involved in the above formulas refers to reduction, while the lower one refers to oxidation.

The sMH model, unlike the BV theory predicts a potential dependence of the transfer coefficient leading to curved Tafel plots[31-33]. The predictions can be linked to the BV theory as follows. From the analysis of the electrochemically irreversible ButlerVolmer kinetics for an oxidation process, 


$$
\beta=\frac{R T}{F} \frac{\partial \ln \left|I_{o x}\right|}{\partial E}=\frac{R T}{F} \frac{\partial \ln \left|k_{o x}^{B V}\right|}{\partial E}
$$

where according to the Arrhenius equation,

$$
k_{o x}^{B V}=A \exp \left(-\frac{\Delta G^{\dagger}}{R T}\right)
$$

in which $A$ is the pre-exponential factor.

Together with Eq. (9), the link between Butler-Volmer kinetics and symmetric MarcusHush theory is given by:

$$
\beta=\frac{1}{2}\left(1+\frac{\Delta G}{\lambda}\right)
$$

where for the electrode process,

$$
\Delta G=-F\left(E-E_{f}^{0}\right)
$$

Hence,

$$
\beta=\frac{\lambda+F E_{f}^{0}}{2 \lambda}-\frac{F}{2 \lambda} E
$$

This relationship in principle enables the extraction of values for $\lambda$ and $E_{f}^{0}$ from experimental voltammograms[34]. Note that Eq. (19) is derived assuming the symmetric form of the $\mathrm{MH}$ theory which is reflected in the limiting value of 0.5 for the transfer coefficient as the reorganization energy increases to a large value or when $E=E_{f}^{0}$.

Hitherto, numerous systems have been successfully interpreted by the sMH model[17, 35-37] and surface bound couples in particular. The application for solution phase processes is more limited largely since diffusional effects take over with increasing over-potential before significant Marcusian behaviour becomes apparent. Accordingly 
the difference between $\mathrm{sMH}$ and $\mathrm{BV}$ theory is not great although often BV gives a slightly better fit with experiment[38-41]. However if the assumption that the reactant and product Gibbs energy parabolae have the same curvature is relaxed - leading to asymmetric MH (aMH) theory then the superiority of the latter is apparent $[22,42]$.

\section{Modelling of voltammetry}

We next see how the different theories are reflected in predicted voltammograms recorded at macro-electrodes. It is assumed that the following is limited to diffusioncontrolled charge transfer processes so giving the transport equations for the species A and B according to Fick's law:

$$
\begin{aligned}
& \frac{\partial[A]}{\partial t}=D_{A} \frac{\partial^{2}[A]}{\partial x^{2}} \\
& \frac{\partial[B]}{\partial t}=D_{B} \frac{\partial^{2}[B]}{\partial x^{2}}
\end{aligned}
$$

where $[A]$ and $[B]$ are the concentrations of $\mathrm{A}$ and $\mathrm{B}$ respectively, $D_{A}$ and $D_{B}$ the diffusion coefficients of $\mathrm{A}$ and $\mathrm{B}$ respectively, $t$ the time and $x$ the distance normal to the electrode.

Digisim[43], a commercial finite difference based simulation software, was employed for modelling the cyclic voltammetry. This is based on the symmetric Marcus-Hush theory. Our aim was to explore the extent to which the peak current in cyclic voltammetry might be limited by finite electron transfer kinetics in the same way that micro-disc limiting currents can be so influenced[19]. The one-electron redox reaction $(A-e=B)$ is considered to take place at the surface of a planar macrodisc electrode (diameter: $3.0 \mathrm{~mm}$ ), where the mass-transport limited flux is mainly contributed by 
linear diffusion. The concentrations $[A]$ and $[B]$ were set as $1.5 \mathrm{mM}$ and 0 respectively, and the diffusion coefficients $D_{A}$ and $D_{B}$ were both $1 \times 10^{-5} \mathrm{~cm}^{2} / \mathrm{s}$. A value for the formal potential $E_{f}^{0}$ of 0 was assumed and a value of $1 \mathrm{eV}$ for the reorganization energy $\lambda$.

Figure 1 shows the effect of changing the electrochemical rate constant $k_{0}$ keeping the other parameters. For fast $k_{0}$ the electrochemically reversible limit is reached with a peak current consistent with the Randles-Sevcik equation:

$$
I_{p}=2.69 \times 10^{5} S[A] D_{A}^{1 / 2} v^{1 / 2}
$$

where given the geometric area $S$ of the electrode and the applied scan rate $v$, the peak current $I_{p}$ only depends on the bulk concentration and diffusional properties of the reactant. Moreover the peak-to-peak potential separation of $57 \mathrm{mV}$ observed is again consistent with the established analytical theory[44, 45]. On decreasing the value of $k_{0}$ the wave becomes irreversible and the peak current decreases with the forward peak shifting anodically as over-potential develops.

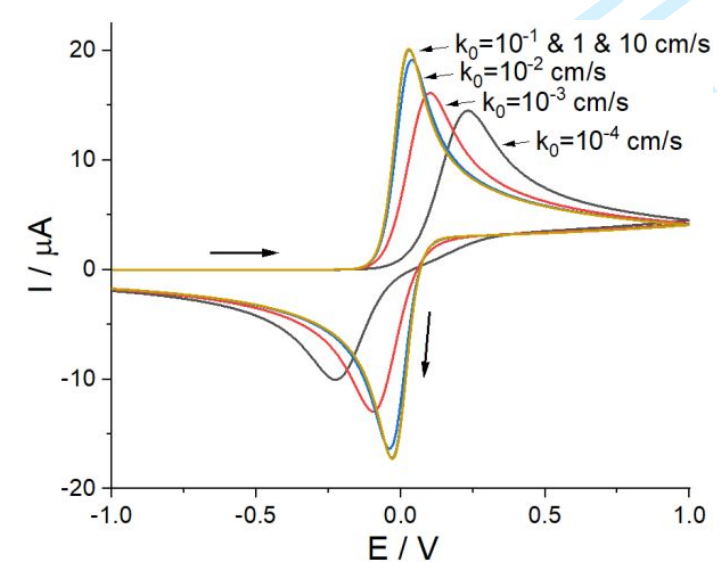

Figure 1. Theoretical voltammetry of the oxidation of A to B at a planar macrodisc electrode (diameter: $3 \mathrm{~mm}$ ) using symmetric Marcus-Hush model for studying the effect of $\boldsymbol{k}_{0}$. Parameters: $E_{f}^{0}=0 ; \lambda=1 \mathrm{eV} ; k_{0}=10^{-4}, 10^{-3}, \ldots 10 \mathrm{~cm} / \mathrm{s} ;[A]=1.5 \mathrm{mM}$ and $[B]=0 ; D_{A}=D_{B}=$ 
$1 \times 10^{-5} \mathrm{~cm}^{2} / \mathrm{s} ; \quad \boldsymbol{v}=50 \mathrm{mV} / \mathrm{s}$.

Next the effect of the reorganization energy $\lambda$ on the typical cyclic voltammetry was studied. Figure 2 shows how the voltammetry responds to different values of the reorganization energy, $\lambda=0.2,0.4$ and $1 \mathrm{eV}$, for various values of $k_{0}$ in the range $10^{-4}$ to $10 \mathrm{~cm} / \mathrm{s}$. In general it is apparent that for low $k_{0}, \lambda$ has the same influence on both oxidative and reductive peaks which are decreased in size significantly and broadened with a decrease of $\lambda$. This reflects the asymptotic behaviour of sMH kinetics that as $\lambda$ decreases, the rate constants tends to level off at smaller overpotentials and give rise to smaller limiting current values[46]. For a fixed reorganization energy an increase in $k_{0}$ causes the voltammetric shape to become increasingly independent of $\lambda$, as the system becomes electrochemically reversible.
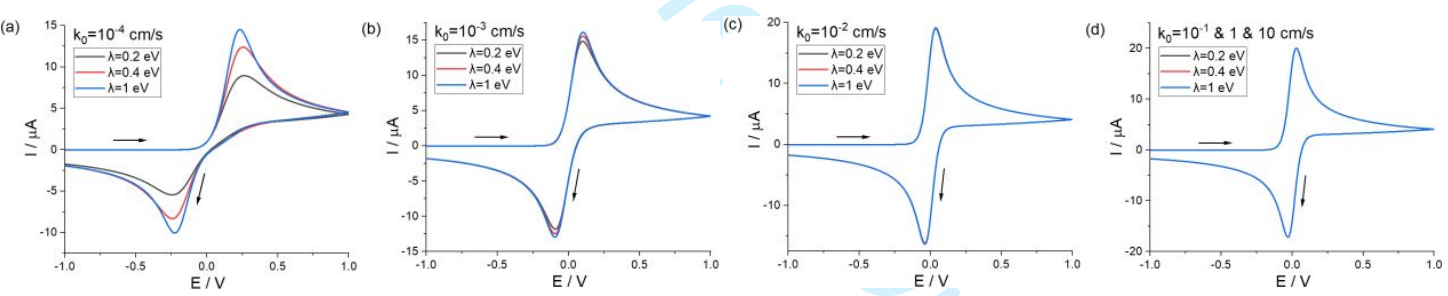

Figure 2. Theoretical voltammetry of the oxidation of A to B at a planar macrodisc electrode (diameter: $3 \mathrm{~mm}$ ) using symmetric Marcus-Hush model for studying the effect of $\lambda$. Parameters: $E_{f}^{0}=0 ; \lambda=0.2,0.4$ and $1 \mathrm{eV} ;[A]=1.5 \mathrm{mM}$ and $[B]=0 ; D_{A}=D_{B}=1 \times 10^{-5} \mathrm{~cm}^{2} / \mathrm{s} ;$ $\boldsymbol{v}=50 \mathrm{mV} / \mathrm{s} ; \quad \boldsymbol{k}_{0}=$ (a) $10^{-4}$, (b) $10^{-3}$, (c) $10^{-2}$, (d) $10^{-1}, 1$ and $10 \mathrm{~cm} / \mathrm{s}$.

Then the disparity between the sMH and BV models in the variation of $\beta$ with $E$ was explored. Figure 3a presents the simulated voltammograms for the fully irreversible limit based on the BV (dotted) and sMH (dashed: $\lambda=0.5 \mathrm{eV}$ and solid: $\lambda=1 \mathrm{eV}$ ) models with identical parameters, respectively, except for the choice of the reorganization energy and the transfer coefficient. The values of $1 \mathrm{eV}$ and 0.5 were 
selected for comparison. The analysis over the current range of $1 \%$ to $99 \%$ of the peak current, namely the highlighted red parts of the figure, was conducted to give a plot of $\beta$ with $E$ as shown in Figure 3b, where $\beta$ was obtained from the derivative of $\ln I$ with $E$ according to $\beta=\frac{R T}{F} \frac{d \ln I}{d E}$. For BV, at very low currents, the measured anodic transfer coefficient $\beta$ approaches the input value of 0.5 in the case of BV kinetics and the expected limit for sMH kinetics. A gradual deviation from the limit of 0.5 with the rise of overpotential is seen, especially from 0.3 to $0.45 \mathrm{~V}$, on account of the depletion of the reactant at the electrode surface, reflecting an increasing mass transport effect. Hence, for practical analysis, usually the $10 \% \sim 30 \%$ of the peak current is taken for Tafel analysis where the mass transport effect is minimal compared to the electrode kinetics since the diffusion layer is thin. Close to the peak current, $\beta$ approaches zero. For sMH (both $\lambda=0.5$ and $1 \mathrm{eV}$ ), $\beta$ was observed to decrease almost linearly with the increasingly positive overpotential, even under conditions where diffusional effects are expected to be negligible (on the basis of the BV simulations) in accordance with the linear relationship described in Eq. (21). This observation contrasts markedly from the BV model for a fully irreversible process.

(a)

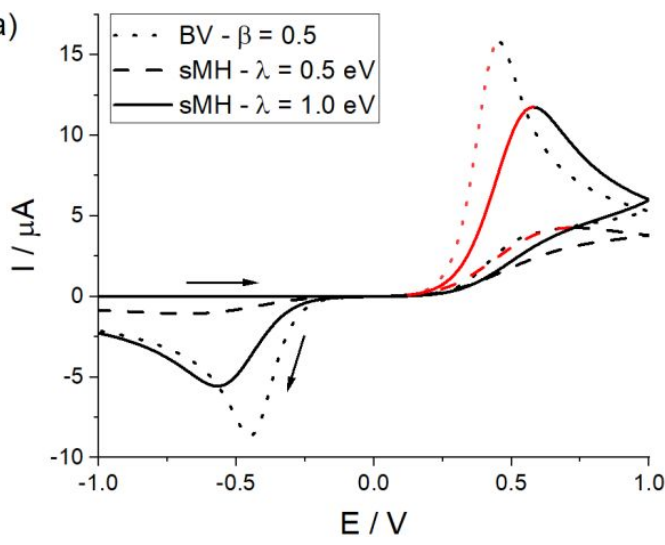

(b)

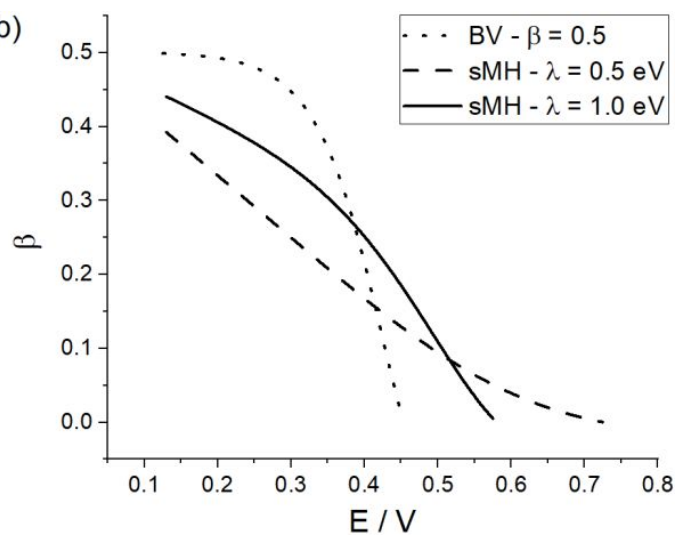

Figure 3. (a) Theoretical voltammetry of the oxidation of A to B at a planar macrodisc electrode 
(diameter: $3 \mathrm{~mm}$ ) for studying the variation of $\beta$ with $E$ in the fully irreversible limit using the Butler-Volmer model with $\beta=0.5$ (dotted) and symmetric Marcus-Hush model with $\lambda=0.5$ (dashed) and $1 \mathrm{eV}$ (solid). (b) Plot of $\beta$ versus $E$ analysed from the highlighted red parts of the voltammograms. Parameters: $E_{f}^{0}=0 ; k_{0}=10^{-6} \mathrm{~cm} / \mathrm{s} ;[A]=1.5 \mathrm{mM}$ and $[B]=0 ; D_{A}=$ $D_{B}=1 \times 10^{-5} \mathrm{~cm}^{2} / \mathrm{s} ; \quad \boldsymbol{v}=50 \mathrm{mV} / \mathrm{s}$.

\section{Results and discussion}

The electro-oxidation of hydrazine $\left(\mathrm{N}_{2} \mathrm{H}_{4}\right)$ was studied via cyclic voltammetry $(\mathrm{CV})$ at a Glassy Carbon electrode to probe the intrinsic electron transfer kinetics of hydrazine. Figure 4a presents the voltammograms obtained at $50 \mathrm{mV} / \mathrm{s}$ in a $1.5 \mathrm{mM}$ aqueous solution of $\mathrm{N}_{2} \mathrm{H}_{4}$ supported by $0.1 \mathrm{M}$ PBS (pH 9). A fully irreversible wave with a peculiarly elongated shape was observed in the presence of $\mathrm{N}_{2} \mathrm{H}_{4}$ (solid) at $0.68 \mathrm{~V}$ vs SCE corresponding to four-electron hydrazine oxidation[5, 47], whereas no voltammetric features were shown in the absence of $\mathrm{N}_{2} \mathrm{H}_{4}$ (dashed). The effect of scan rate was investigated where an increase in the oxidative peak current was observed as shown in Figure $4 \mathrm{~b}$. The inset clearly indicates that the corresponding peak current was in direct proportion to the square root of scan rate, suggesting a diffusion-controlled process. 
(a)

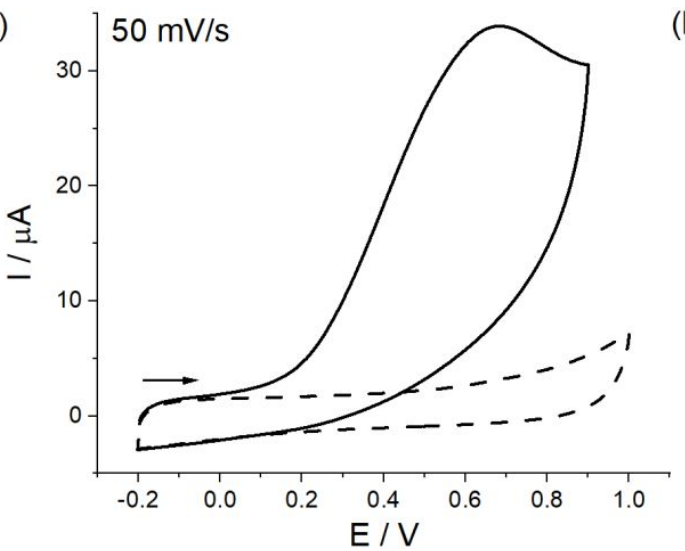

(b)

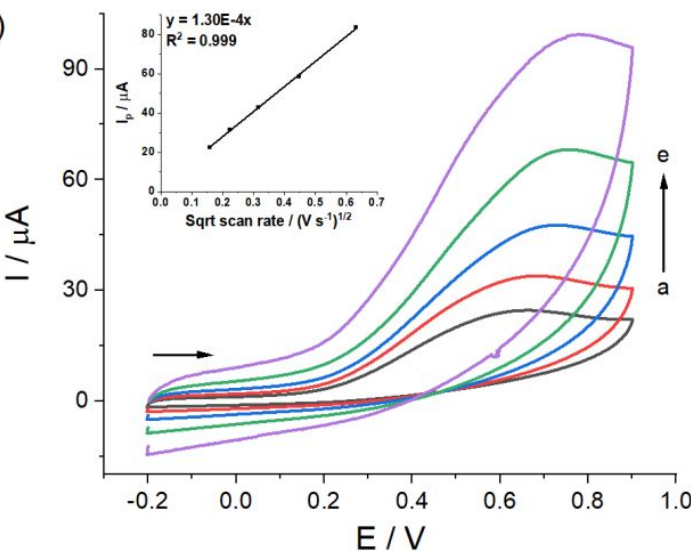

Figure 4. (a) Voltammograms on a GC electrode at $50 \mathrm{mV} / \mathrm{s}$ in $0.1 \mathrm{M}$ PBS (pH 9) with $1.5 \mathrm{M}$ hydrazine (solid) and without hydrazine (dashed). (b) Voltammograms recorded at different scan rates of 25, 50, 100, 200 and $400 \mathrm{mV} / \mathrm{s}$ (from a to e). The start of the voltammetric scans is indicated.

Tafel analysis was then applied for further exploring the electron transfer kinetics of the hydrazine oxidation. The region from $10 \%$ to $30 \%$ of the peak current was taken for analysis in order to avoid any influence from background currents (especially at very low overpotentials) or reactant depletion effects due to the limitation of mass transport.[48]. The local Tafel slopes at each potential were found by evaluating the derivative $\beta=\frac{R T}{F} \frac{\partial \ln \left|I_{o x}\right|}{\partial E}$. The Tafel plots (black) and the part of the voltammogram selected for fitting (red) for each scan rate are shown in Figure 5 where the anodic transfer coefficient $\beta$ was observed to be strongly dependent on the potential $E$ in a linearly negative relationship. This is exactly consistent with the symmetric MarcusHush (sMH) theory as depicted in Figure 3. Table 1 shows the evaluation of the formal potential and the reorganization energy for each of the scan rates studied. There is no systematic variation with scan rate of either parameter, thus $\lambda$ is $c a .0 .35 \mathrm{eV}$ and $E_{f}^{0}$ is $c a$. $0.14 \mathrm{~V}$, consistent with the absence of concentration depletion effects. Analogous experiments were conducted for different concentrations of hydrazine, for different 
buffer capacities and for different levels of supporting electrolytes as summarised in Table 2 where again a potential dependent transfer coefficient and a similar reorganization energy was observed.

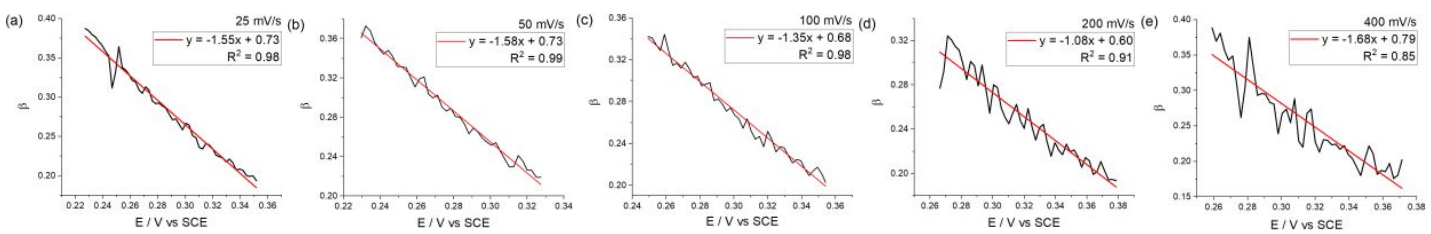

Figure 5. Plots of the measured anodic transfer coefficient $\beta$ and the potential $E$ in the range from $10 \%$ to $30 \%$ of the voltammetric peak current.

Table 1 Measured values of reorganization energy and formal potential for hydrazine oxidation at each scan rate on $0.1 \mathrm{M}$ PBS

\begin{tabular}{cccccc|c}
\hline $\mathrm{v} / \mathrm{mV} \mathrm{s}^{-1}$ & 25 & 50 & 100 & 200 & 400 & Average \\
\hline$\lambda / \mathrm{eV}$ & 0.32 & 0.32 & 0.37 & 0.46 & 0.30 & $0.35 \pm 0.07$ \\
$\mathrm{E}_{\mathrm{f}}^{0} / \mathrm{V}$ & 0.15 & 0.14 & 0.13 & 0.09 & 0.17 & $0.14 \pm 0.03$ \\
\hline
\end{tabular}

Table 2 Measured average values of reorganization energy and formal potential for hydrazine oxidation in various electrolytes

\begin{tabular}{cccc}
\hline Electrolyte & Initial concentration of $\mathrm{N}_{2} \mathrm{H}_{4} / \mathrm{mM}$ & $\lambda / \mathrm{eV}$ & $\mathrm{E}_{\mathrm{f}}^{0} / \mathrm{V}$ \\
\hline $0.1 \mathrm{M} \mathrm{PBS}$ & 1.5 & $0.35 \pm 0.07$ & $0.14 \pm 0.03$ \\
$0.3 \mathrm{M} \mathrm{PBS}$ & 1 & $0.44 \pm 0.08$ & $0.10 \pm 0.04$ \\
$0.5 \mathrm{M} \mathrm{PBS}$ & 1 & $0.47 \pm 0.06$ & $0.08 \pm 0.04$ \\
$0.5 \mathrm{M} \mathrm{PBS}+0.2 \mathrm{M} \mathrm{KCl}$ & 1 & $0.44 \pm 0.08$ & $0.09 \pm 0.05$ \\
\hline
\end{tabular}

Clearly the oxidation of hydrazine is not controlled by the Butler-Volmer (BV) kinetics but the sMH. This is primarily due to the fact that the reorganisation energy is sufficiently small that the differences between BV and sMH become apparent; this low value in turn might arise if the hydrazine molecule and the corresponding radical cation 
have a similar structure (bond lengths and angles) and solvation. Note that the formal potential applies to the thermodynamics of the first electron transfer assumed to be ratedetermining, and not the overall 4 electron process. Note also that the inferred formal potential is highly approximate not least since it assumes that symmetric MH theory operates and that the transfer coefficient at zero over-potential is exactly 0.5 .

It is also noteworthy that the re-organisation energy is rather low as compared to some outer sphere redox couples as analysed via the MH theory, as summarised in the Table S2 in the SI Section 2. Perusal of Eq. (21) shows that it is this low value, which amplifies the Marcusian effects and leads to the drawn out behaviour of the observed voltammetric waves. Moreover the inappropriate application of BV kinetics explains the diversity of the values of the oxidative transfer coefficient reported in the literature and highlighted in the Table S1. It was also highlighted that the literatures report a wide diversity of diffusion coefficients, however the method of data analysis used to infer the $\mathrm{MH}$ character of the electron transfer is independent of any value for the diffusion coefficient. Furthermore the range of literature values can be appreciated by exploring, via simulation, the effect of the reorganization energy for a fixed diffusion coefficient on the peak current for a slow $k_{0}$ value of $10^{-6} \mathrm{~cm} / \mathrm{s}$. An arbitrary value of $10^{-5} \mathrm{~cm}^{2} / \mathrm{s}$ was selected for the diffusion coefficient given the large range of literature values (see Table S1). As depicted in Figure 6, the magnitude of the peak current significantly increases with the rise of the reorganization energy, and the linearity between the peak current and square scan rate is strongly associated with $\lambda$ due to the asymptotic behaviour of sMH kinetics. As $\lambda$ increases, the sMH theory tends to collapse into the 
BV. However for the value of the reorganization energy inferred above for the hydrazine oxidation system it is evident that plots of limiting current versus the square root of scan rate cannot be expected to quantitatively follow the Randles-Sevcik equation: $I_{p}=2.99 \times 10^{5} n \beta^{1 / 2} S[A] D_{A}{ }^{1 / 2} v^{1 / 2}$. In this equation $n$ is the number of electrons transferred[49], and is derived for a fully irreversible process following Butler-Volmer kinetics with a potential independent value of the transfer coefficient. This inapplicability in part explains the range of diffusion coefficients in the literature as well as the range of single transfer coefficient values reported. Note that if sMH rather than BV kinetics operates then a rigorous linear dependence of the peak current in the square root of scan rate is not expected[40] although the deviation is typically not great.

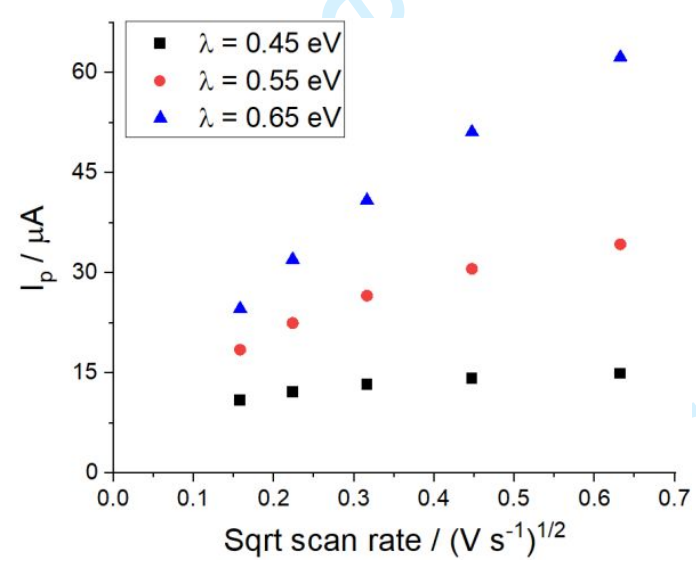

Figure 6. Plots of theoretical oxidative peak current and square root of scan rate from the simulation at a planar macrodisc electrode (diameter: $3 \mathrm{~mm}$ ) using symmetric Marcus-Hush model for studying the effect of $\lambda$ on the peak current. Reaction mechanism: $A-4 e=B$. Parameters: $E_{f}^{0}=0 \mathrm{~V}$; $\lambda=0.45,0.55$ and $0.65 \mathrm{eV} ; k_{0}=10^{-6} \mathrm{~cm} / \mathrm{s}$ for the rate-determining electron transfer step; $[A]$ $=1.5 \mathrm{mM}$ and $[B]=0 ; \quad D_{A}=D_{B}=1 \times 10^{-5} \mathrm{~cm}^{2} / \mathrm{s} ; \quad \boldsymbol{v}=100 \mathrm{mV} / \mathrm{s}$. 


\section{Conclusions}

In this work, the intrinsic electron transfer kinetics of the hydrazine oxidation reaction was investigated on the Glassy Carbon electrode in 0.1 M PBS (pH 9). Tafel analysis for the voltammetry on the GC electrode reveals a negatively linear correlation between the anodic transfer coefficient and the potential, deviating distinctly from the wellrecognized Butler-Volmer theory. The symmetric Marcus-Hush theory was adopted to describe the voltammetry. The reorganization energy was estimated to be $0.35 \pm 0.07$ eV from the relationship $\beta=\frac{\lambda+F E_{f}^{0}}{2 \lambda}-\frac{F}{2 \lambda} E$. The potential dependence of the transfer coefficient and the inapplicability of the Randles-Sevcik equation in the fully irreversible Butler-Volmer limit may explain in part the diversity of values for the transfer and diffusion coefficients present in the literature.

\section{Conflict of interest}

The authors declare that they have no conflict of interest.

\section{References}

[1] Furst A, Berlo RC, Hooton S. Hydrazine as a reducing agent for organic compounds (catalytic hydrazine reductions). Chem Rev, 1965, 65(1): 51-68

[2] Lu Z, Sun M, Xu T, et al. Superaerophobic electrodes for direct hydrazine fuel cells. $A d v$ Mater, 2015, 27(14): 2361-2366

[3] Wang T, Wang Q, Wang Y, et al. Atomically dispersed semimetallic selenium on porous carbon membrane as an electrode for hydrazine fuel cells. Angew Chem Int Ed Engl, 2019, 58(38): 13466-13471

[4] Feng G, Kuang Y, Li P, et al. Single crystalline ultrathin nickel-cobalt alloy nanosheets array for direct hydrazine fuel cells. Adv Sci, 2017, 4(3): 1600179

[5] Wang B, Cao X. The anodic oxidation of hydrazine on glassy carbon electrode. Electroanalysis, 1992, 4(7): 719-724 
[6] Baron R, Šljukić B, Salter C, et al. Development of an electrochemical sensor nanoarray for hydrazine detection using a combinatorial approach. Electroanalysis, 2007, 19(10): 10621068

[7] Xiong L, Compton RG. Amperometric gas detection: A review. Int J Electrochem Sci, 2014, $9(7152-7181$

[8] Bruice TC, Bruno J, Chou W-S. Nucleophilic displacement reactions at the thiol-ester bond of $\delta$-thiolvalerolactone. J Am Chem Soc, 1963, 85(11): 1659-1669

[9] Moreno JH, Diamond JM. Role of hydrogen bonding in organic cation discrimination by gallbladder epithelium. Nature, 1974, 247(5440): 368-369

[10] Hayon E, Simic M. Intermediates produced from the one-electron oxidation of hydrazine. Evidence for the formation and decay of tetrazane and triazene. J Am Chem Soc, 1972, 94(1): $42-47$

[11] Korovin N, Yanchuk B. Hydrogen sorption by palladium in hydrazine electro-oxidation. Electrochim Acta, 1970, 15(4): 569-580

[12] Rosca V, Duca M, de Groot MT, et al. Nitrogen cycle electrocatalysis. Chem Rev, 2009, 109(6): 2209-2244

[13] Kocak CC, Altin A, Aslisen B, et al. Electrochemical preparation and characterization of gold and platinum nanoparticles modified poly (taurine) film electrode and its application to hydrazine determination. Int J Electrochem Sci, 2016, 11(233-249

[14] Maduraiveeran G, Ramaraj R. Gold nanoparticle-based sensing platform of hydrazine, sulfite, and nitrite for food safety and environmental monitoring. Journal of Analytical Science and Technology, 2017, 8(1): 1-10

[15] Koçak S, Aslışen B. Hydrazine oxidation at gold nanoparticles and poly (bromocresol purple) carbon nanotube modified glassy carbon electrode. Sensors and Actuators B: Chemical, 2014, 196(610-618

[16] Batchelor-McAuley C, Kätelhön E, Barnes EO, et al. Recent advances in voltammetry. ChemistryOpen, 2015, 4(3): 224-260

[17] Chidsey CE. Free energy and temperature dependence of electron transfer at the metalelectrolyte interface. Science, 1991, 251(4996): 919-922

[18] Laborda E, Henstridge MC, Batchelor-McAuley C, et al. Asymmetric marcus-hush theory for voltammetry. Chem Soc Rev, 2013, 42(12): 4894-4905

[19] Feldberg SW. Implications of marcus- hush theory for steady-state heterogeneous electron transfer at an inlaid disk electrode. Anal Chem, 2010, 82(12): 5176-5183

[20] Ding Z, Quinn BM, Bard AJ. Kinetics of heterogeneous electron transfer at liquid/liquid interfaces as studied by secm. The Journal of Physical Chemistry B, 2001, 105(27): 6367-6374 [21] Wang Y, Laborda E, Henstridge MC, et al. The use of differential pulse voltammetries to discriminate between the butler-volmer and the simple marcus-hush models for heterogeneous electron transfer: The electro-reduction of europium (iii) in aqueous solution. $J$ Electroanal Chem, 2012, 668(7-12

[22] Laborda E, Henstridge MC, Compton RG. Asymmetric marcus theory: Application to electrode kinetics. $J$ Electroanal Chem, 2012, 667(48-53

[23] Butler JAV. The mechanism of overvoltage and its relation to the combination of hydrogen atoms at metal electrodes. T Faraday Soc, 1932, 28(379-382 
[24] Erdey-Grúz T, Volmer M. Zur theorie der wasserstoff überspannung. Zeitschrift für physikalische Chemie, 1930, 150(1): 203-213

[25] Bordwell F, Boyle Jr WJ. Acidities, broensted coefficients, and transition state structures for 1-arylnitroalkanes. J Am Chem Soc, 1972, 94(11): 3907-3911

[26] Formosinho SJ. Theoretical studies of proton-transfer reactions. Journal of the Chemical Society, Perkin Transactions 2, 1987, 1): 61-66

[27] Marcus RA. On the theory of oxidation-reduction reactions involving electron transfer. I. The Journal of chemical physics, 1956, 24(5): 966-978

[28] Eberson L, Gonzalez-Luque R, Lorentzon J, et al. The ab initio calculation of inner sphere reorganization energies of inorganic redox couples. J Am Chem Soc, 1993, 115(7): 2898-2902 [29] Hush N. Adiabatic rate processes at electrodes. I. Energy-charge relationships. The Journal of Chemical Physics, 1958, 28(5): 962-972

[30] Hush N. Electron transfer in retrospect and prospect: 1: Adiabatic electrode processes. $J$ Electroanal Chem, 1999, 460(1-2): 5-29

[31] Appleby AJ, Zagal JH. Free energy relationships in electrochemistry: A history that started in 1935. Journal of Solid State Electrochemistry, 2011, 15(7-8): 1811-1832

[32] Bai P, Bazant MZ. Charge transfer kinetics at the solid-solid interface in porous electrodes. Nature communications, 2014, 5(1): 1-7

[33] Laborda E, Henstridge MC, Compton RG. Giving physical insight into the butler-volmer model of electrode kinetics: Part 2-nonlinear solvation effects on the voltammetry of heterogeneous electron transfer processes. J Electroanal Chem, 2012, 681(96-102

[34] Savéant J-M. Elements of molecular and biomolecular electrochemistry. Willey- $\mathrm{CCH}, \mathrm{New}$ Jersey, 2006,

[35] Forster RJ, Faulkner LR. Electrochemistry of spontaneously adsorbed monolayers. Equilibrium properties and fundamental electron transfer characteristics. J Am Chem Soc, 1994, 116(12): 5444-5452

[36] Madhiri N, Finklea HO. Potential-, ph-, and isotope-dependence of proton-coupled electron transfer of an osmium aquo complex attached to an electrode. Langmuir, 2006, 22(25): 10643-10651

[37] Kozub BR, Henstridge MC, Batchelor-McAuley C, et al. Edge plane pyrolytic graphite electrode covalently modified with 2-anthraquinonyl groups: Theory and experiment. Chemphyschem, 2011, 12(15): 2806-2815

[38] Henstridge MC, Wang Y, Limon-Petersen JG, et al. An experimental comparison of the marcus-hush and butler-volmer descriptions of electrode kinetics applied to cyclic voltammetry. The one electron reductions of europium (iii) and 2-methyl-2-nitropropane studied at a mercury microhemisphere electrode. Chemical Physics Letters, 2011, 517(1-3): 2935

[39] Laborda E, Wang Y, Henstridge MC, et al. Quantitative weaknesses of the marcus-hush theory of electrode kinetics revealed by reverse scan square wave voltammetry: The reduction of 2-methyl-2-nitropropane at mercury microelectrodes. Chemical Physics Letters, 2011, 512(1-3): 133-137

[40] Henstridge MC, Laborda E, Dickinson EJ, et al. Redox systems obeying marcus-hushchidsey electrode kinetics do not obey the randles-ševčík equation for linear sweep voltammetry. $J$ Electroanal Chem, 2012, 664(73-79 
[41] Suwatchara D, Rees NV, Henstridge MC, et al. Experimental comparison of the butlervolmer and marcus-hush-chidsey formalisms of electrode kinetics: The reduction of cyclooctatetraene at mercury hemispherical electrodes via cyclic and square wave voltammetries. J Electroanal Chem, 2012, 665(38-44

[42] Zeng Y, Bai P, Smith RB, et al. Simple formula for asymmetric marcus-hush kinetics. $J$ Electroanal Chem, 2015, 748(52-57

[43] Rudolph M, Reddy DP, Feldberg SW. A simulator for cyclic voltammetric responses. Anal Chem, 1994, 66(10): 589A-600A

[44] Compton RG, Banks CE. Understanding voltammetry. Place Published: World Scientific,2018:

[45] Elgrishi N, Rountree KJ, McCarthy BD, et al. A practical beginner's guide to cyclic voltammetry. Journal of Chemical Education, 2018, 95(2): 197-206

[46] Batchelor-McAuley C, Kätelhön E, Barnes EO, et al. Recent advances in voltammetry. ChemistryOpen, 2015, 4(3): 224

[47] Wang Y, Wan Y, Zhang D. Reduced graphene sheets modified glassy carbon electrode for electrocatalytic oxidation of hydrazine in alkaline media. Electrochem Commun, 2010, 12(2): 187-190

[48] Li D, Lin C, Batchelor-McAuley C, et al. Tafel analysis in practice. J Electroanal Chem, 2018, 826(117-124

[49] Miao R, Chen L, Shao L, et al. Electron transfer to decorated graphene oxide particles. Angewandte Chemie International Edition, 2019, 58(36): 12549-12552 


\section{Table of Contents graphic}

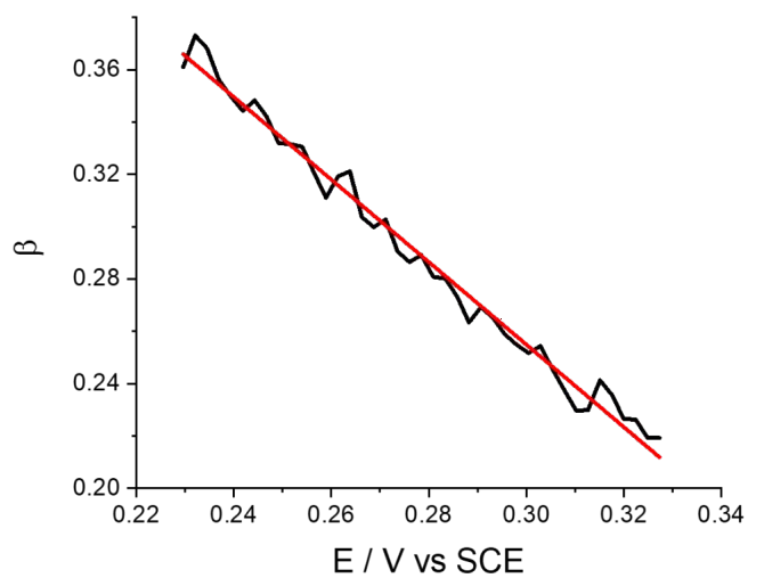

20 


\section{Supporting Information}

\section{Section 1: Literature data reported for the hydrazine oxidation}

Table S1 Literature data reported for the hydrazine oxidation

\begin{tabular}{|c|c|c|c|c|c|c|}
\hline Electrode & Electrolyte & pH & Electrochemical Method & $\mathrm{D}\left(\mathrm{cm}^{2} / \mathrm{s}\right)$ & $\boldsymbol{\beta}$ & Ref. \\
\hline Pt microdisc electrode & $0.1 \mathrm{M} \mathrm{HClO}_{4}$ & 1 & RDE voltammetry & $1.40 \mathrm{E}-5$ & / & {$[1]$} \\
\hline Pd nanoparticles decorated poly-3,4-ethylenedioxythiophene & $0.2 \mathrm{M}$ PBS & 6.9 & RDE voltammetry & $1.20 \mathrm{E}-5$ & 0.27 & {$[2]$} \\
\hline Pd nanoparticles decorated poly-3,4-ethylenedioxythiophene & $0.2 \mathrm{M}$ PBS & 6.9 & RDE voltammetry & $1.20 \mathrm{E}-5$ & 0.28 & [3] \\
\hline Pd nanoparticles decorated gaur gum & $0.1 \mathrm{M}$ PBS & 7 & Chronoamperometry & $2.83 \mathrm{E}-6$ & 0.67 & {$[4]$} \\
\hline Pd nanoparticles decorated ethylenediamine cellulose & $0.1 \mathrm{M}$ PBS & 7 & Chronoamperometry & $2.30 \mathrm{E}-5$ & l & [5] \\
\hline Pd-Au nanoparticles & $0.1 \mathrm{M}$ PBS & 7 & Chronoamperometry & $2.61 \mathrm{E}-5$ & 0.46 & [6] \\
\hline Pd nanoparticles decorated multiwalled carbon nanotubes & $0.1 \mathrm{M}$ PBS & 7 & Chronoamperometry & $1.10 \mathrm{E}-5$ & 0.55 & [7] \\
\hline Au nanoparticles decorated polypyrrole nanowire & $0.1 \mathrm{M}$ PBS & 7 & Chronoamperometry & $2.50 \mathrm{E}-5$ & 0.48 & [8] \\
\hline $\mathrm{Au}$ nanoparticles decorated $\mathrm{TiO}_{2}$ nanotubes & $0.1 \mathrm{M}$ PBS & 7 & Chronoamperometry & 4.10E-5 & 0.21 & {$[9]$} \\
\hline Au nanoparticles decorated multiwalled carbon nanotubes & $0.1 \mathrm{M}$ PBS & 7 & Chronoamperometry & $2.05 \mathrm{E}-5$ & 0.59 & {$[10]$} \\
\hline Hematoxylin multi-wall carbon nanotubes & $0.1 \mathrm{M}$ PBS & 7 & Chronoamperometry & $4.58 \mathrm{E}-6$ & 0.55 & {$[11]$} \\
\hline Co(II) complex multi-wall carbon nanotube & $0.1 \mathrm{M}$ PBS & 7 & Chronoamperometry & $4.50 \mathrm{E}-6$ & 0.53 & {$[12]$} \\
\hline p-aminophenol-modified multiwall carbon nanotubes & $0.1 \mathrm{M}$ PBS & 7 & Chronoamperometry & $9.50 \mathrm{E}-6$ & 0.30 & {$[13]$} \\
\hline rGO- $\mathrm{Co}_{3} \mathrm{O}_{4} @ \mathrm{Au}$ nanocomposite & $0.1 \mathrm{M}$ PBS & 7.2 & Chronoamperometry & 7.82E-7 & / & {$[14]$} \\
\hline Au nanoparticles decorated choline film & $0.1 \mathrm{M}$ PBS & 7.4 & Chronoamperometry & $2.46 \mathrm{E}-5$ & 0.50 & {$[15]$} \\
\hline Au nanoparticles decorated single-walled carbon nanohorns film & $0.1 \mathrm{M}$ PBS & 7.4 & Chronoamperometry & 4.43E-6 & / & [16] \\
\hline Au nanocage decorated graphene & $0.1 \mathrm{M}$ PBS & 7.4 & Chronoamperometry & $2.32 \mathrm{E}-6$ & 0.54 & {$[17]$} \\
\hline Chlorogenic acid & $0.15 \mathrm{M}$ PBS & 7.5 & Chronoamperometry & $8.20 \mathrm{E}-6$ & 0.45 & {$[18]$} \\
\hline Curcumin multi-wall carbon nanotubes & $0.5 \mathrm{M}$ PBS & 8 & Chronoamperometry & $2.45 \mathrm{E}-6$ & 0.45 & {$[19]$} \\
\hline Carbon nanotubes and terpyridine manganese(II) complex & $0.1 \mathrm{M}$ PBS & 8 & RDE voltammetry & $1.54 \mathrm{E}-6$ & 0.60 & {$[20]$} \\
\hline
\end{tabular}


Pt rotating disk electrode

Porous Au membranes

Overoxidized polypyrrole (OPPy) modified glassy carbon

Reduced graphene sheets

Copper nanotubes on graphene paper

Copper (hydr)oxide modified copper electrode

$\mathrm{Ni}(\mathrm{II})$-baicalein complex modified multi-wall carbon nanotube paste electrode

(5,10,15,20-tetra(4-sulfophenyl) porphyrin-nickel

Ni-based ternary alloy electrode $(\mathrm{G} / \mathrm{NiCuCo})$

\begin{tabular}{cccccc}
0.05 PBS & 8 & RDE voltammetry & $6.40 \mathrm{E}-6$ & $/$ & {$[21]$} \\
$0.1 \mathrm{M} \mathrm{PBS}$ & 8.5 & Chronoamperometry & $1.65 \mathrm{E}-5$ & $/$ & {$[22]$} \\
$\begin{array}{c}\text { 0.1 M ammonium } \\
\text { buffer solution }\end{array}$ & 9 & Chronoamperometry & $3.10 \mathrm{E}-5$ & 0.46 & {$[23]$} \\
$0.1 \mathrm{M} \mathrm{KOH}$ & 13 & Chronoamperometry & $2.20 \mathrm{E}-5$ & 0.48 & {$[24]$} \\
$0.1 \mathrm{M} \mathrm{KOH}$ & 13 & Chronocoulometry & $2.10 \mathrm{E}-5$ & 0.50 & {$[25]$} \\
$0.1 \mathrm{M} \mathrm{NaOH}$ & 13 & Chronoamperometry & $3.00 \mathrm{E}-5$ & 0.51 & {$[26]$} \\
$0.1 \mathrm{M} \mathrm{NaOH}$ & 13 & Chronoamperometry & $3.58 \mathrm{E}-5$ & 0.35 & {$[27]$} \\
$0.1 \mathrm{M} \mathrm{NaOH}$ & 13 & Chronoamperometry & $4.19 \mathrm{E}-6$ & $/$ & {$[28]$} \\
$0.1 \mathrm{M} \mathrm{NaOH}$ & 13 & Chronoamperometry & $6.28 \mathrm{E}-6$ & $/$ & {$[29]$} \\
\hline
\end{tabular}




\section{Section 2: Literature values of the outer-sphere reorganization energy values}

Table S2 Literature values of the outer-sphere reorganization energy for redox couples

\begin{tabular}{|c|c|c|c|c|c|c|c|c|c|c|}
\hline Redox species & $\mathrm{O}_{2}^{-} / \mathrm{O}_{2}$ & $\mathrm{O}_{3} / \mathrm{O}_{3}^{-}$ & $\mathrm{N}_{3} / \mathrm{N}_{3}^{-}$ & $\mathrm{CO}_{2} / \mathrm{CO}_{2}^{-}$ & $\mathrm{SO}_{2} / \mathrm{SO}_{2}^{-}$ & $\mathrm{ClO}_{2} / \mathrm{ClO}_{2}^{-}$ & $\mathrm{NO}^{+} / \mathrm{NO}$ & $\mathrm{NO}_{2}^{+} / \mathrm{NO}_{2}$ & $\mathrm{Fe}^{2+} / 3+$ & $\mathrm{Cr}^{2+} / 3^{+}$ \\
\hline$\lambda_{\text {outer }} / \mathrm{eV}$ & 2.30 & 2.02 & 1.93 & 2.22 & 2.20 & 2.01 & 2.11 & 1.55 & 1.50 & 1.52 \\
\hline Ref. & {$[30]$} & [30] & [30] & [30] & [30] & {$[30]$} & [31] & {$[32]$} & [33] & [33] \\
\hline Redox species & $\mathrm{Mn}^{2+} / 3+$ & $\mathrm{V}^{2+} \beta+$ & $\mathrm{Co}^{2+} \beta^{+}$ & $\mathrm{Fe}(\text { phen })^{2+/ 3+}$ & $\left.\mathrm{Ru}(\mathrm{bpy})_{3}\right)^{2+/ 3+}$ & $\mathrm{Ru}(\mathrm{en})_{3}{ }^{2+/ 3+}$ & $\mathrm{Ru}\left(\mathrm{NH}_{3}\right)_{6}{ }^{2+/ 3+}$ & $\mathrm{Fe}(\mathrm{CN})_{6}^{4-3-}$ & $\mathrm{Ru}\left(\mathrm{H}_{2} \mathrm{O}\right)_{6}{ }^{2+/ 3+}$ & $\mathrm{Cr}\left(\mathrm{OH}_{2}\right)_{6}{ }^{2+/ 3+}$ \\
\hline$\lambda_{\text {outer }} / \mathrm{eV}$ & 1.51 & 1.49 & 1.52 & 0.57 & 0.57 & 0.92 & 1.16 & 0.86 & 1.20 & 1.04 \\
\hline Ref. & [33] & [33] & [33] & [34] & [34] & [34] & [34] & [34] & [34] & [35] \\
\hline
\end{tabular}

\section{References}

[1] Chen C-H, Jacobse L, McKelvey K, et al. Voltammetric scanning electrochemical cell microscopy: Dynamic imaging of hydrazine electrooxidation on platinum electrodes. Anal Chem, 2015, 87(11): 5782-5789

[2] Kondratiev VV, Babkova TA, Tolstopjatova EG. Pedot-supported pd nanoparticles as a catalyst for hydrazine oxidation. Journal of Solid State Electrochemistry, 2013, 17(6): 1621-1630

[3] Babkova T, Kondratiev V, Shevaldysheva D. Oxidation of hydrazine on poly-3, 4-ethylenedioxythiophene polymer films with inclusions of palladium nanoparticles. Russ J Electrochem +, 2013, 49(3): 259-264

[4] Rastogi PK, Ganesan V, Krishnamoorthi S. Palladium nanoparticles decorated gaur gum based hybrid material for electrocatalytic hydrazine determination. Electrochim Acta, 2014, 125(593-600

[5] Ahmar H, Keshipour S, Hosseini H, et al. Electrocatalytic oxidation of hydrazine at glassy carbon electrode modified with ethylenediamine cellulose immobilized palladium nanoparticles. J Electroanal Chem, 2013, 690(96-103 
[6] Shamsipur M, Karimi Z, Tabrizi MA, et al. Electrocatalytic determination of traces of hydrazine by a glassy carbon electrode modified with palladium-gold nanoparticles. Electroanalysis, 2014, 26(9): 1994-2001

[7] Haghighi B, Hamidi H, Bozorgzadeh S. Sensitive and selective determination of hydrazine using glassy carbon electrode modified with pd nanoparticles decorated multiwalled carbon nanotubes. Analytical and bioanalytical chemistry, 2010, 398(3): 1411-1416

[8] Li J, Lin X. Electrocatalytic oxidation of hydrazine and hydroxylamine at gold nanoparticle-polypyrrole nanowire modified glassy carbon electrode. Sensors and Actuators B: Chemical, 2007, 126(2): 527-535

[9] Hosseini M, Momeni MM, Faraji M. Electro-oxidation of hydrazine on gold nanoparticles supported on tio2 nanotube matrix as a new high active electrode. Journal of Molecular Catalysis A: Chemical, 2011, 335(1-2): 199-204

[10]Hamidi H, Bozorgzadeh S, Haghighi B. Amperometric hydrazine sensor using a glassy carbon electrode modified with gold nanoparticledecorated multiwalled carbon nanotubes. Microchimica Acta, 2017, 184(11): 4537-4543

[11]Zare HR, Nasirizadeh N. Hematoxylin multi-wall carbon nanotubes modified glassy carbon electrode for electrocatalytic oxidation of hydrazine. Electrochim Acta, 2007, 52(12): 4153-4160

[12]Benvidi A, Kakoolaki P, Zare HR, et al. Electrocatalytic oxidation of hydrazine at a co (ii) complex multi-wall carbon nanotube modified carbon paste electrode. Electrochim Acta, 2011, 56(5): 2045-2050

[13]Ensafi AA, Lotfi M, Karimi-Maleh H. New modified-multiwall carbon nanotubes paste electrode for electrocatalytic oxidation and determination of hydrazine using square wave voltammetry. Chinese Journal of Catalysis, 2012, 33(2-3): 487-493

[14] Shahid MM, Rameshkumar P, Basirunc WJ, et al. An electrochemical sensing platform of cobalt oxide@ gold nanocubes interleaved reduced graphene oxide for the selective determination of hydrazine. Electrochim Acta, 2018, 259(606-616

[15]Li J, Xie H, Chen L. A sensitive hydrazine electrochemical sensor based on electrodeposition of gold nanoparticles on choline film modified glassy carbon electrode. Sensors and Actuators B: Chemical, 2011, 153(1): 239-245

[16]Zhao S, Wang L, Wang T, et al. A high-performance hydrazine electrochemical sensor based on gold nanoparticles/single-walled carbon nanohorns composite film. Applied Surface Science, 2016, 369(36-42

[17]Daemi S, Ashkarran AA, Bahari A, et al. Fabrication of a gold nanocage/graphene nanoscale platform for electrocatalytic detection of hydrazine. Sensors and Actuators B: Chemical, 2017, 245(55-65

[18] Golabi S, Zare H. Electrocatalytic oxidation of hydrazine at a chlorogenic acid (cga) modified glassy carbon electrode. $J$ Electroanal Chem, 1999, 465(2): 168-176 
[19]Zheng L, Song J-f. Curcumin multi-wall carbon nanotubes modified glassy carbon electrode and its electrocatalytic activity towards oxidation of hydrazine. Sensors and Actuators B: Chemical, 2009, 135(2): 650-655

[20]Kamyabi M, Narimani O, Monfared HH. Electrocatalytic oxidation of hydrazine using glassy carbon electrode modified with carbon nanotube and terpyridine manganese (ii) complex. J Electroanal Chem, 2010, 644(1): 67-73

[21]Kleijn SE, Serrano-Bou B, Yanson AI, et al. Influence of hydrazine-induced aggregation on the electrochemical detection of platinum nanoparticles. Langmuir, 2013, 29(6): 2054-2064

[22] Yan X, Meng F, Cui S, et al. Effective and rapid electrochemical detection of hydrazine by nanoporous gold. $J$ Electroanal Chem, 2011, 661(1): 44-48

[23] Majidi MR, Jouyban A, Asadpour-Zeynali K. Electrocatalytic oxidation of hydrazine at overoxidized polypyrrole film modified glassy carbon electrode. Electrochim Acta, 2007, 52(21): 6248-6253

[24] Wang Y, Wan Y, Zhang D. Reduced graphene sheets modified glassy carbon electrode for electrocatalytic oxidation of hydrazine in alkaline media. Electrochem Commun, 2010, 12(2): 187-190

[25] Gao H, Wang Y, Xiao F, et al. Growth of copper nanocubes on graphene paper as free-standing electrodes for direct hydrazine fuel cells. The Journal of Physical Chemistry C, 2012, 116(14): 7719-7725

[26] Karim-Nezhad G, Jafarloo R, Dorraji PS. Copper (hydr) oxide modified copper electrode for electrocatalytic oxidation of hydrazine in alkaline media. Electrochim Acta, 2009, 54(24): 5721-5726

[27]Zheng L, Song J-f. Ni (ii)-baicalein complex modified multi-wall carbon nanotube paste electrode toward electrocatalytic oxidation of hydrazine. Talanta, 2009, 79(2): 319-326

[28]Kazemi S, Hosseinzadeh B, Zakavi S. Electrochemical fabrication of conducting polymer of ni-porphyrin as nano-structured electrocatalyst for hydrazine oxidation. Sensors and Actuators B: Chemical, 2015, 210(343-348

[29] Jafarian M, Rostami T, Mahjani M, et al. A low cost and highly active non-noble alloy electrocatalyst for hydrazine oxidation based on nickel ternary alloy at the surface of graphite electrode. J Electroanal Chem, 2016, 763(134-140

[30]Bennett LE, Warlop P. Electron transfer to ozone: Outer-sphere reactivities of the ozone/ozonide and related non-metal redox couples. Inorganic Chemistry, 1990, 29(10): 1975-1981

[31] Sandall JP. The mechanism of aromatic nitration in solution: Marcus theory and semiempirical molecular orbital calculations on no $2+$ and no+ as one-electron oxidants. Journal of the Chemical Society, Perkin Transactions 2, 1992, 10): 1689-1693 
[32]Lund T, Eberson L. Experimental determination of the reorganization energy of theno2+/no2 redox couple. Comparison withtheory. Journal of the Chemical Society, Perkin Transactions 2, 1997, 8): 1435-1444

[33]Rosso KM, Rustad JR. Ab initio calculation of homogeneous outer sphere electron transfer rates: Application to m (oh2) 63+/2+ redox couples. The Journal of Physical Chemistry A, 2000, 104(29): 6718-6725

[34]Delahay P. Reply to "contribution of inner-sphere reorganization in electron transfer reaction in solution" by sum khan and jo'm. Bockris. Chemical Physics Letters, 1983, 99(1): 87-88

[35] Sutin N, Weaver MJ, Yee EL. Correlations between outer-sphere self-exchange rates and reaction entropies for some simple redox couples. Inorganic Chemistry, 1980, 19(4): 1096-1098 